\title{
Attitudes About Sex and Marital Sexual Behavior in Hai Duong Province, Vietnam
}

\author{
Sharon Ghuman
}

\begin{abstract}
This study examines attitudes concerning sexual relations outside marriage and levels of marital sexual activity using data from married individuals from Hai Duong Province collected in 2001. Among individuals who live in urban areas, have more schooling, and were married after the late 1980s, acceptance is growing concerning intimate behavior without marital commitment and having sex with a future spouse. Schooling, urban residence, and recent marriage have stronger associations with less conservative attitudes among men than among women. Even among younger and bettereducated respondents, acceptance of premarital and extramarital sex generally remains below a majority. The reported level of premarital sex is higher among men than among women, and lower than available estimates from other parts of Asia and the developing world. The reported level of sexual activity within marriage in Hai Duong Province is similar to that observed elsewhere, including Thailand and the United States. The incidence of sexual activity declines with age, and at all ages men are more likely than women to report having sex with their spouse. The implications of these gender differences in sexual attitudes and behavior are considered. (STUDIES IN FAMILY PlanNing 2005; 36[2]: 95-106)
\end{abstract}

Since the early 1990s, concern has grown about increasing levels of premarital sex, unintended pregnancies, abortion, and sexually transmitted diseases among Asian young people. Within the context of northern Vietnam, the shift to a market-based economy and to increased exposure to the outside world initiated by the government in the 1980s (doi moi) is thought to have produced a greater acceptance of sex before marriage among the young (Efroymson 1996; Haub and Huong 2003; Khuat 2003; Mensch et al. 2003a). However, information is lacking about the sexual behavior of both unmarried and married individuals in Vietnam. Recent studies indicate scant support for the popular assumption that sexual activity is widespread among adolescents in Vietnam (Mensch et al. 2003a). Rates of premarital sex, HIV infection, pregnancy, and birth among people younger than 25 are substantially lower than such rates in neighboring countries and in much of the rest of the developing world (Hardee et al. 2003; Haub and Huong 2003; Mensch et al. 2003a). The few studies that examine reasonably complete data on induced abortion in Vietnam indicate that most abortions are performed for married women (Goodkind 1994).

Sharon Ghuman is Postdoctoral Fellow, University of Michigan, Population Studies Center, 426 Thompson Street, Ann Arbor, MI 48106. E-mail: sharongu@isr.umich.edu.
In this context of heightened concerns about the sexuality of unmarried young people, the sexuality of married people within Vietnam (and in developing-country settings in general) has received little attention from researchers. A significant gap in knowledge of Vietnamese sexuality exists as a result, because available studies indicate that sexual activity in Vietnam occurs largely within and not outside of marriage (see, for example, Mensch et al. 2003a). The study of sexual activity among married adults is valuable for understanding an important dimension of individual health and well-being, for drawing comparisons with other settings, and for elucidating how gender, age, and socioeconomic characteristics shape sexual expression. Research on married individuals' attitudes and behaviors related to sex before marriage is useful for informing the current debate about whether a progressive liberalization of prevailing sexual norms is occurring in Vietnam.

This study examines attitudes and behaviors concerning physical intimacy and sex before, within, and outside marriage among a sample of married men and women in Hai Duong Province, located about 60 kilometers (37 miles) east of Hanoi. The reported incidence of premarital sex and sexual activity within marriage is analyzed. Although the study is limited to reports from a single province and findings are not, therefore, generalizable to the entire country, it makes several contributions. The extent of changes in views concerning sexual behav- 
ior are considered for a series of marriage cohorts from before (1965-85) and after (1986-2001) the official start of the doi moi period. The findings document reported levels of premarital sexual activity for individuals in these cohorts to indicate whether, as is often suggested, sex before marriage has become more common in recent years. The results provide information about the relationships between gender, age, and the incidence and frequency of marital sex, as well as about which partner initiates sexual activity. The study examines whether schooling, socioeconomic status, or migration from rural to urban areas engenders changes in attitudes and behavior concerning sexual activity in Hai Duong.

\section{Background}

Confucianism, a key source of social organization in Vietnam, has contributed to stringent social and familial disapproval of extramarital sex, and has conferred a high value on remaining chaste until marriage, particularly for women (Eisen 1984; Khuat 1998; Gammeltoft 2002). Until the 1960s, the close involvement of parents in choosing their children's spouses, based on such criteria as compatibility of parental socioeconomic status or political affiliations, also aided in regulating premarital sexual contact (Bélanger and Khuat 1996). Historical and current accounts of village rituals involving worship of genitalia, games of suggestive contact between men and women, and literary works indicate a degree of sexual openness in Vietnam (Khuat 1998; Gammeltoft 2002). The rise of French print media and intellectuals' push for greater sexual freedom in the early twentieth century also introduced notions of romance and personal choice in spouse selection (Khuat 1998; Gammeltoft 2002). Whether these notions extended to the general population is unclear. Pham (1999) suggests that their influence was limited to the urban elite and that sexual standards in Vietnam remained highly conservative.

The Democratic Republic of Vietnam that came to power in 1945 issued decrees on marriage in 1950 and 1959 that, in principle, gave individuals complete control over their choice of a marriage partner. Evidence has documented a sharp decline in the incidence of marriage arranged by parents in some northern Vietnamese provinces during the 1959-70 period (Goodkind 1996). The rise of a modern marriage custom is relevant to the extent that it encourages more sex within (and possibly before) marriage (Rindfuss and Morgan 1983). Accordingly, Goodkind (1995) infers that the positive association between choosing a spouse and earlier onset of first birth in a northern Vietnamese province is due to greater frequency of sexual intercourse shortly after marriage than was the norm in the past. Although the government advocated gender equality on several fronts including marriage, education, and employment, this position is argued to have had little effect on sexual mores. The expression of female beauty or sexuality was discouraged by the state as a vestige of Western culture. The government emphasized instead the role of women as reproducers and workers contributing to various war efforts (Eisen 1984; Khuat 1998; Pham 1999; Gammeltoft 2002).

In addition to inferences based on historical records, popular literature, and newspaper articles, current knowledge of sexuality in Vietnam is generally drawn from studies of sex, abortion, and HIV infection among women and adolescents. ${ }^{1}$ The greater exposure to Western messages and images through the media ushered in by doi moi is argued to have led to an increase in permissiveness concerning dating and premarital sex (Vu 1996; Bélanger and Khuat 1998 and 1999; Khuat 1998 and 2003; Long et al. 2000; Gammeltoft 2002 and 2003; Haub and Huong 2003). Younger individuals are considered more likely to engage in sexual contact or premarital sex, particularly as a precursor to marriage with their partner (Khuat 1998; Gammeltoft 2003). Sexual activity is likely to be seen as a legitimate way to express love and provide pleasure or to ensure that a potential husband and wife are physically compatible (Khuat 1998; Bélanger and Khuat 1999; Gammeltoft 2002). Sexual experimentation is thought to be greater within the anonymity of the city, where communal monitoring of individuals is lower than in villages and where an active dating culture exists (Gammeltoft 2003). In part as a reaction to doi moi and in an attempt to control the spread of AIDS, the government and the media have continued to advance traditional social values and discourage intravenous drug use, prostitution, premarital sex, and excess consumerism (for example, see Chittick 1996; Barr 1997; Long et al. 2000).

Several studies suggest that in Vietnam, as in other settings, distinct gender-role differences can be found in the expression of sexuality (for example, see Khuat 1998 and 2003; see also Knodel et al. 1999 on such differences found in Thailand). Although arguably the sexual reserve of women may be, in part, biological, it is thought to be encouraged by socialization in Vietnam in which reticence, gentility of manner, and obedience are emphasized for women but not for men (Gammeltoft 2001; Rydstrom 2003). In qualitative studies, women report feeling considerable anxiety about violating established moral norms and incurring social disapproval by engaging in premarital sex (Efroymson et al. 1997; Bélanger and Khuat 1999; Gammeltoft 2002; Go et al. 2002). ${ }^{2}$ Women relinquish their virginity before marriage with considerable ambivalence and often do so to ensure a boyfriend's loyalty or marriage proposal (Bélanger and Khuat 1998 and 
1999). People of both sexes assume that men have an inherent need for and enjoyment of sex that women do not share (or at least feel uncomfortable expressing freely) (Efroymson et al. 1997; Pham 1999; Go et al. 2002). Descriptions of rural family life from the twentieth century suggest that marital sex is an awkward, infrequent, and unpleasant event for women, that they seldom initiate sexual activity and view it solely as a marital obligation (Pham 1999). The apparent lack of privacy within villages may also prevent frequent marital sex (Hy 1992). The greater acceptance of extramarital sex for men than for women, resulting from men's presumed inherent need for sexual variety or their indifference toward their spouse, is hypothesized to have increased in recent years (Khuat 1998; Pham 1999).

The studies reviewed above rely on anthropological observations, focus-group discussions, or convenience samples of women and adolescents in urban areas. Although they provide interesting hypotheses, their claims regarding recent changes in sexual behavior and attitudes in Vietnam require further study. Has there been a significant liberalization of attitudes about premarital and extramarital sex since the economic renovation? What is the nature of sexual activity within marriage in Vietnam? Do men and women differ in their attitudes or in their sexual behavior within marriage? Has premarital sex become more common in recent years? Answers to these questions are presented based on data collected in 2001 from married men and women living in a province near Hanoi.

\section{Methodology}

This analysis is based on a survey of two rural (Thank Khe and Thanh Hai) and two urban (Binh Han and Pham Ngu Lao) communes in Hai Duong Province conducted in February 2001 by the Institute of Sociology in Hanoi. The total sample consists of 800 married respondents (399 men and 401 women) ranging in age from 24 to 56. Survey participants had lived with their spouses for at least the six months prior to the survey. This survey was a pilot study for two larger surveys of family change subsequently completed in the Red River Delta and Ho Chi Minh City and surrounding provinces. The design of the survey was intended to maximize detection of changes in the Vietnamese family over time. Equal numbers were selected of men and women, rural and urban residents, and individuals in two birth cohorts: 1946-56 and 196676 . Because of cost considerations, individuals from the middle birth cohort (1957-65) were not sampled. To the extent that behavioral change is fairly linear with respect to time, and because a longer time gap between separate cohorts is useful for detecting such changes, a focus on obtaining respondents from two cohorts at either end of the 30-year time span starting in 1946 was a sensible strategy. In this study, the sample is divided into four marriage cohorts: (1) those married between 1965 and 1975 (the period of the American War); (2) those married at the time of Vietnamese reunification (1976-85); (3) those married between 1986 and 1992; and (4) those married between 1993 and 2000. The fourth category allows us to consider separately those who were married when economic reforms had been underway for some time.

In the survey, respondents were asked whether three sorts of behaviors related to sex were acceptable at the time of their marriage: (1) having an intimate relationship that involved being seen together or openly expressing affection by holding hands, kissing, and hugging with an individual they did not intend to marry; (2) engaging in sexual intercourse with an individual they planned to marry; and (3) having sexual relations with someone other than their spouse. Possible responses were "strongly disagree," "disagree," "agree somewhat," and "strongly agree." Although the "don't know" response was available, few respondents chose this response, which is excluded from the results. For each behavior, respondents were asked two versions of the question, one with a male and one with a female referent. For example, they were asked if it was acceptable for a woman to express intimacy with a man she did not intend to marry and if it was acceptable for a man to behave similarly with a woman he did not intend to marry. The respondents reported their understanding of the acceptability of each type of behavior at the time of their marriage, providing a specific time referent so that respondents could be arrayed by marriage cohort as a way to assess changes in attitudes over time. Chronbach's alpha for the items has a value of $0.76 .^{3}$ The normative response for all items is "strongly disagree," and the items are dichotomized so that this response is compared with all others.

Based on the information gathered for the survey, two types of sexual behaviors can be examined for the sample of married men and women. First, respondents report whether they had sexual intercourse for the first time before they were married. If they report that they did, they are asked if the person they had sex with was married or unmarried, and whether they subsequently married that person. Second, the survey provides information about the proportion of respondents who had sex with their spouse in the month before the survey and about the frequency of this intercourse (that is, once a month, two to three times per month, or once or twice a week, and three to four times a week). Those who had sex with their spouse in the past month are asked who initiated sexual relations (the respondent, both partners, 
or the spouse). Insecurity about spousal infidelity is addressed with a question asking if the respondent worries that his or her spouse is romantically interested in anyone else when they are apart.

The relationship between marriage cohort and attitudes about sex is examined, with a focus on the association of marital sexual behavior and the age of respondents and their spouses. Respondents' year of marriage and age are highly correlated $(\mathrm{r}=-0.91)$, and better-educated individuals are also more likely than others to be younger and married for shorter durations. Thus, it is often difficult to attribute any associations for marriage cohort, age, or schooling to each of these influences by itself. The less conservative attitudes of those married for shorter periods of time, for example, may well reflect their being younger and better educated. Also, shifts in attitudes or behavior among those married after the late 1980s could be occurring irrespective of doi moi, and to what extent these changes are attributable to this event alone is difficult to assess.

In addition to marriage cohort and age, educational attainment is considered here as a categorical variable (that is, primary and lower secondary levels compared with upper secondary or higher levels), as are residential history and an index of household assets and housing quality used as a proxy for socioeconomic status. As described in Filmer and Pritchett (2001), the index of household assets is obtained as the first principal component of 14 items. These include the household's ownership of 11 items: a sewing machine, television, video cassette recorder, stereo, radio, bicycle, fan, furniture, cupboard, motorcycle, and telephone. The index also contains items on the availability of piped water, a flush toilet, and the number of rooms in the household. ${ }^{4}$

Since the early 1980s, reforms such as the private contracting of land in rural areas, the elimination of subsidies and price controls, and the lifting of restrictions on markets and transport in the private sector have encouraged migration from rural to urban areas, particularly for people aged 20 to 29 (Dang et al. 1997). Logically, and as suggested by Gammeltoft (2003), continuous exposure to urban society may be related to more liberal attitudes about sex than would be encountered in a rural area. Accordingly, the attitudes and behaviors of individuals who have always resided in urban areas are examined to determine whether they are significantly less conservative than those of people who either spent their childhood (age 5 to 15) in a rural area and moved to an urban commune or have always resided in a rural commune.

Table 1 shows percentage distributions for selected characteristics by sex for the rural, urban, and total samples. Residents of urban areas and men are more likely to complete the upper secondary level of schooling com-
Table 1 Percentage distribution of survey respondents, by selected characteristics, according to residence and sex, Hai Duong Province, Vietnam, 2001

\begin{tabular}{|c|c|c|c|c|c|c|}
\hline \multirow[b]{2}{*}{ Characteristics } & \multicolumn{2}{|c|}{ Rural } & \multicolumn{2}{|c|}{ Urban } & \multicolumn{2}{|c|}{ Total } \\
\hline & Men & Women & Men & Women & Men & Women \\
\hline \multicolumn{7}{|l|}{$\begin{array}{l}\text { Educational level } \\
\text { completed }\end{array}$} \\
\hline Primary & 4.5 & 9.6 & 0.5 & 4.5 & 2.5 & 7.0 \\
\hline Lower secondary & 64.7 & 76.8 & 34.8 & 36.8 & 49.7 & 56.7 \\
\hline Upper secondary+ & 30.8 & 13.6 & 64.6 & 58.7 & 47.7 & 36.2 \\
\hline Total & 100.0 & 100.0 & 100.0 & 100.0 & 100.0 & 100.0 \\
\hline $\begin{array}{l}\text { Household wealth } \\
\text { index }\end{array}$ & -1.43 & -1.56 & 1.52 & 1.49 & 0.039 & -0.039 \\
\hline \multicolumn{7}{|l|}{ Residential history ${ }^{b}$} \\
\hline $\begin{array}{l}\text { in urban area } \\
\text { Grew up in rural area } \\
\text { but lives in urban area }\end{array}$ & - & - & 33.2 & 25.4 & 16.5 & 12.7 \\
\hline $\begin{array}{l}\text { Grew up and lives } \\
\text { in rural area }\end{array}$ & 100.0 & 100.0 & - & 0.0 & 50.1 & 49.9 \\
\hline Total & 100.0 & 100.0 & 100.0 & 100.0 & 100.0 & 100.0 \\
\hline \multicolumn{7}{|l|}{ Marriage cohort } \\
\hline 1965-75 & 28.0 & 32.0 & 17.6 & 18.4 & 22.8 & 25.2 \\
\hline $1976-85$ & 22.0 & 20.0 & 28.6 & 28.9 & 25.3 & 24.4 \\
\hline $1986-92$ & 31.5 & 36.5 & 14.1 & 26.9 & 22.8 & 31.7 \\
\hline $1993-2000$ & 18.5 & 11.5 & 39.7 & 25.9 & 29.1 & 18.7 \\
\hline Total & 100.0 & 100.0 & 100.0 & 100.0 & 100.0 & 100.0 \\
\hline Age (mean) & 40.3 & 39.5 & 40.8 & 39.5 & 40.5 & 39.5 \\
\hline $\begin{array}{l}\text { Age difference between } \\
\text { spouses (mean years) } \\
\text { (N) }\end{array}$ & $\begin{array}{l}2.23 \\
(200)\end{array}$ & $\begin{array}{l}-2.29 \\
(200)\end{array}$ & $\begin{array}{r}3.31 \\
(199)\end{array}$ & $\begin{array}{l}-3.21 \\
(201)\end{array}$ & $\begin{array}{l}2.77 \\
(399)\end{array}$ & $\begin{array}{l}-2.76 \\
(401)\end{array}$ \\
\hline
\end{tabular}

$-=$ Not applicable

${ }^{a}$ The first principal component of variables described in text (see also text footnote 4). The overall mean is zero by construction; the standard deviation is 2.18 33 percent of the variance in the items is captured by the index. ${ }^{b}$ Refers to period between ages 5 and 15. Three individuals who migrated from urban to rural areas are included as having grown up and resided in rural communes.

pared with rural respondents and women. Educational attainment beyond primary level in these settings is substantially higher than that of the aggregate population of the Red River Delta or of rural and urban areas in Vietnam as a whole (Committee for Population, Family, and Children and ORC Macro 2002). The negative value for the index of household assets and housing quality in rural areas indicates a lower standard of living there than in urban communes. About two-thirds of men and three-fourths of women surveyed in the urban areas spent the ages of five to 15 in a rural area and subsequently migrated to an urban commune. Migration from urban to rural areas is rare in this sample (see Table 1, note $b$ ). The average age of the male and female respondents is 40.5 and 39.5 years, respectively.

Because of the private and sensitive nature of sexual behavior, reports based on face-to-face interviews are prone to systematic measurement error of various kinds (Dare and Cleland 1994; Call et al. 1995; Goodkind and Anh 1997; Turner et al. 2001; and Mensch et al. 2003b). Respondents, particularly women, may be reluctant to report sexual activity because they feel embarrassed to disclose such information to an interviewer, especially 
in a context where premarital sex remains socially unacceptable. Although face-to-face interviews minimize nonresponse rates, they have been shown to produce underreporting of early sexual experience among young men in Vietnam (Goodkind and Anh 1997). ${ }^{5}$ In Kenya, a comparison of face-to-face interviews, paper-and-pencil questionnaires, and audio-assisted methods that afford more privacy by allowing respondents to hear (and answer) questions with a computer showed that adolescent girls are less likely to report engaging in a variety of sexual behaviors in a face-to-face or self-administered questionnaire than with an audio-assisted method (Mensch et al. 2003b). The reverse was found among boys' reports of engaging in premarital sex and having girlfriends, findings that suggest that boys exaggerate participation in sexual activity in face-to-face interviews. The high levels of disagreement with the attitudinal measures examined here may reflect a normatively acceptable response in a society where casual sex is portrayed unfavorably in official parlance (Goodkind and Anh 1997). The lower reported incidence of premarital sex among older individuals who were married before the mid-1980s may be due to their greater difficulty with recall of, or their greater tendency to underrreport, sexual experience compared with that of younger respondents. In the absence of repeated measurements using different data-collection instruments (for example, selfadministered questionnaires, audio-assisted techniques, and biomarker data), and because of the lack of multiple indicators for certain attitudes (such as anxiety about spousal infidelity), assessing directly the measurement properties of these items is difficult. For marital sexual activity, statistical adjustments and tabulations by age indirectly reveal information about sex-specific sources of systematic measurement error.

Privacy of survey responses may be less of a concern among married individuals, who are generally more willing to report premarital sexual activity than are unmarried respondents (see Xenos 1997 and Mensch et al. 2003a for illustrations of this point from the Philippines and Vietnam, respectively). To the extent that many associations between the attitudinal items and respondents' sex, education, marriage cohort, and urban residence conform to expectations based on findings described in the available literature, the items appear to have criterion-based validity. ${ }^{6}$

\section{Results}

Table 2 presents the proportions of respondents who "strongly disagree" with each of the six attitudinal items on premarital and extramarital sex. Eighty-four and 81 percent of respondents in rural areas express strong disagreement with the notion that intimate behavior without the intention to marry is acceptable. In urban areas, the corresponding percentages are 84 percent and 78 percent for the two items. Significant urban and rural differences are found in the proportion of residents who disapprove of the notion of having premarital sex with a future spouse. Urban respondents, irrespective of the gender referent of the question, are 17 percent less likely than rural respondents to disagree with the notion that sexual intercourse with a future spouse is an acceptable practice. Respondents in both urban and rural areas express strong disapproval of extramarital sex.

Within both rural and urban areas and for virtually all items, women are significantly more likely than men to offer conservative views. For example, in rural areas, women are 12 percent more likely than men to disagree with the idea that sexual intimacy before marriage without commitment is acceptable; in urban areas the difference is 8 and 12 percent. The lowest levels of disagreement with the statements expressing conservative attitudes are found among urban men with regard to having sex with a future spouse (60 percent and 55 percent for each item, respectively). Although women in urban communes are less likely to disapprove of having sex with a future spouse than their rural counterparts, they are still 15-16 percent more likely to disapprove of it than are men living in urban areas. For each pair of items, the difference in disagreement between men and women is not associated with the gender referent for the statement. Table 2 also indicates whether both men and women, respectively, are more likely to disagree with a statement when it has a female referent. The differences in disapproval across item pairs for each sex are not significant.

Table 3 shows the association between strong disagreement with the attitudinal statements selected and characteristics of respondents by sex. The associations do not differ substantially according to the gender referent of the statement. To simplify presentation, for each pair of items on premarital and extramarital sex, the two questions are combined into a single item that contrasts strong disagreement with both statements compared with all other response categories. The results do not differ appreciably if disagreement with each item separately is used instead.

Levels of disagreement are significantly lower among men with at least upper secondary schooling for all items. This pattern is also observed among women for two of the three items. Regardless of their educational level, women express high levels of disagreement with the acceptability of engaging in intimate relations without the intention of marrying. Generally, disagreement has no consistent association with quartiles of the wealth index. 
Table 2 Percentage of survey respondents who "strongly disagree" with attitudinal statements about sexual behavior, by residence and sex, Hai Duong Province, Vietnam, 2001

\begin{tabular}{|c|c|c|c|c|c|c|}
\hline Strongly disagree & $\begin{array}{r}\text { Acceptable for } \\
\text { a woman to be } \\
\text { intimate with a man } \\
\text { she does not } \\
\text { intend to marry }\end{array}$ & $\begin{array}{r}\text { Acceptable for a } \\
\text { man to be intimate } \\
\text { with a woman } \\
\text { he does not } \\
\text { intend to marry }\end{array}$ & $\begin{array}{r}\text { Acceptable for a } \\
\text { young woman to } \\
\text { have sex with a } \\
\text { man she is about } \\
\text { to marry }\end{array}$ & $\begin{array}{r}\text { Acceptable for a } \\
\text { young man to } \\
\text { have sex with a } \\
\text { woman he is } \\
\text { about to marry }\end{array}$ & $\begin{array}{r}\text { Acceptable for a } \\
\text { married woman } \\
\text { to have a sexual } \\
\text { affair with a man } \\
\text { other than her } \\
\text { husband }\end{array}$ & $\begin{array}{r}\text { Acceptable for } \\
\text { a married man } \\
\text { to have a sexual } \\
\text { affair with a } \\
\text { woman other } \\
\text { than his wife }\end{array}$ \\
\hline \multicolumn{7}{|l|}{ Rural } \\
\hline Men & 77.9 & 74.9 & 76.0 & 70.5 & 85.4 & 79.4 \\
\hline Women & 89.9 & 86.9 & 92.5 & 90.4 & 93.0 & 91.0 \\
\hline Total & 84.0 & 81.0 & 84.3 & 80.4 & 89.2 & 85.2 \\
\hline Difference between women and men & $-12.0^{\star *}$ & $-12.0^{\star \star}$ & $-16.5^{\star \star}$ & $-19.9^{\star *}$ & $-7.6^{*}$ & $-11.6^{\star \star}$ \\
\hline $\begin{array}{l}\text { Difference for each item pair (men) } \\
\text { Difference for each item pair } \\
\text { (women) }\end{array}$ & \multicolumn{2}{|r|}{3.0} & \multicolumn{2}{|r|}{2.1} & & $\begin{array}{l}6.0 \\
2.0\end{array}$ \\
\hline \multicolumn{7}{|l|}{ Urban } \\
\hline Men & 79.7 & 72.2 & 59.6 & 55.3 & 82.8 & 78.4 \\
\hline Women & 87.6 & 84.5 & 74.6 & 71.6 & 89.5 & 89.5 \\
\hline Total & 83.7 & 78.4 & 67.2 & 63.5 & 86.2 & 82.2 \\
\hline Difference between women and men & $-7.9^{\star}$ & $-12.3^{\star \star}$ & $-15.0^{\star \star}$ & $-16.3^{\star \star}$ & -6.7 & $-11.1^{*}$ \\
\hline $\begin{array}{l}\text { Difference for each item pair (men) } \\
\text { Difference for each item pair } \\
\text { (women) }\end{array}$ & & 7.5 & \multicolumn{2}{|r|}{3.0} & & 4.4 \\
\hline $\begin{array}{l}\text { Difference between urban and } \\
\text { rural residents }\end{array}$ & 0.3 & 2.6 & $17.1^{\text {** }}$ & $16.9^{* \star}$ & 3.0 & 3.0 \\
\hline
\end{tabular}

Table 3 Percentage of survey respondents who "strongly disagree" with statements about the acceptability of having premarital or extramarital sex, by selected characteristics, according to sex, Hai Duong Province, Vietnam, 2001

\begin{tabular}{|c|c|c|c|c|c|c|}
\hline \multirow[b]{2}{*}{ Characteristic } & \multicolumn{2}{|c|}{$\begin{array}{l}\text { Acceptable to } \\
\text { have intimate } \\
\text { relations with } \\
\text { someone you } \\
\text { do not intend } \\
\text { to marry }\end{array}$} & \multicolumn{2}{|c|}{$\begin{array}{l}\text { Acceptable to } \\
\text { have sex with } \\
\text { someone you } \\
\text { intend to marry }\end{array}$} & \multicolumn{2}{|c|}{$\begin{array}{l}\text { Acceptable to } \\
\text { have sex with } \\
\text { someone other } \\
\text { than spouse }\end{array}$} \\
\hline & Men & Women & Men & Women & Men & Women \\
\hline \multicolumn{7}{|l|}{ Education } \\
\hline $\begin{array}{l}\text { Primary or lower } \\
\text { secondary }\end{array}$ & 81.2 & 85.8 & 69.2 & 85.5 & 82.1 & 90.6 \\
\hline Upper secondary+ & $63.3^{*}$ & 84.8 & $55.0^{* *}$ & $70.8^{* *}$ & $71.4^{*}$ & $82.6^{*}$ \\
\hline \multicolumn{7}{|l|}{$\begin{array}{l}\text { Quartiles of household- } \\
\text { wealth index }\end{array}$} \\
\hline Lowest $^{\mathrm{a}}$ & 69.8 & 82.9 & 58.8 & 91.4 & 70.8 & 89.6 \\
\hline Second & 74.0 & 84.3 & $70.0^{*}$ & 79.4 & $84.0^{*}$ & 90.8 \\
\hline Third & 74.7 & 89.5 & 66.7 & $78.1^{*}$ & 79.2 & 89.5 \\
\hline Highest & 72.4 & 85.0 & 54.3 & $70.9^{\star \star}$ & 74.3 & 80.4 \\
\hline \multicolumn{7}{|l|}{ Residential history } \\
\hline $\begin{array}{l}\text { Grew up and lives in } \\
\text { urban area }\end{array}$ & 63.1 & 86.3 & 48.5 & 62.8 & 72.7 & 78.0 \\
\hline $\begin{array}{l}\text { Grew up in rural area/ } \\
\text { lives in urban area }\end{array}$ & $76.5^{\star}$ & 83.9 & 58.3 & 72.7 & 78.8 & 88.0 \\
\hline $\begin{array}{l}\text { Always lived in a rural } \\
\text { area }\end{array}$ & 73.4 & 86.4 & $69.5^{\star *}$ & $90.5^{\star \star}$ & 77.4 & $90.0^{*}$ \\
\hline \multicolumn{7}{|l|}{ Marriage cohort } \\
\hline $1965-75^{a}$ & 82.4 & 90.1 & 82.4 & 91.1 & 86.8 & 87.1 \\
\hline $1976-85$ & 79.0 & 87.6 & 77.2 & 84.7 & 81.0 & 90.8 \\
\hline 1986-92 & 67.0 & 81.0 & $51.7^{\star \star}$ & $74.6^{\star \star}$ & $71.4^{\star}$ & 87.4 \\
\hline 1993-2000 & $64.0^{*}$ & 84.0 & $41.7^{\star \star}$ & $69.3^{\star \star}$ & $70.4^{\star *}$ & 85.1 \\
\hline
\end{tabular}

For intimate behavior without intent to marry, men who have had continuous exposure to an urban environment express a significantly lower disapproval level (63 percent) than do either those who grew up in rural areas (77 percent) or those who have always lived in rural areas (73 percent). For the statement about having premarital sex with the intention of marrying, 49 percent of men who grew up and live in urban areas express strong disapproval compared with 70 percent of those who have always lived in rural areas. Those who grew up in rural areas express an intermediate level of disagreement at 58 percent and differ significantly from the respondents who have always resided in a rural area. These findings are analogous for women. For extramarital sex, rural residence, regardless of duration, is associated with more conservative views among women than is urban residence.

Marriage cohorts from 1986 onward are significantly less likely than the oldest cohort to profess conservative views, but this relationship is more pronounced among men than among women. Although 82 and 77 percent of men in the pre-doi moi cohorts disagree that sex with someone a person intends to marry is unacceptable, disagreement falls to 52 and 42 percent among men married in more recent years. While about 91 and 85 percent of women married before 1986 express disapproval of a person having sex with a future spouse, a lower percentage of women married after this time (75 and 69 percent) disapprove of this practice. Among those married after 1985, disapproval remains between 25 and 30 percent 
higher than the corresponding percentage of men. Men married after 1985 are considerably less likely than men married earlier to disagree with the idea that casual intimacy or extramarital sex is acceptable; two out of three items show statistically significant decreases in disagreement. Women, by contrast, continue to express conservative opinions about these two behaviors regardless of their marriage cohort. No significant differences are seen in the propensity to disagree between the two groups married after the mid-1980s for any of the items shown.

\section{Marital Sexual Activity}

Figure 1 shows the percentage of married men and women who report having had sex with their spouse in the past month by age group. As shown in previous studies conducted in several countries, sexual activity declines with age, particularly after about age 40 (Call et al. 1995; Caraël 1995; Knodel and Chayovan 2001). This pattern is thought to be a product of the biological consequences of aging such as declining health and lower testosterone levels), of social taboos about sexual activity among older people, and of couple-specific factors such as habituation to sex with one's spouse (Marsiglio and Donnelly 1991; Knodel and Chayovan 2001).

The figure indicates that women are less likely than men to report having had sex in the month prior to the survey at all ages (see also Table 4). A similar gender gap in reported levels of marital sex after age 50 also has been observed in Thailand (Knodel and Chayovan 2001). The observed gender gap is most pronounced after age 49; women 50 and older report rates of marital sex that are between 15 and 20 percent lower than the rates reported

Figure 1 Percentage of married survey respondents who reported having sex with spouse in the month prior to the survey, by age and sex, Hai Duong Province, Vietnam, 2001

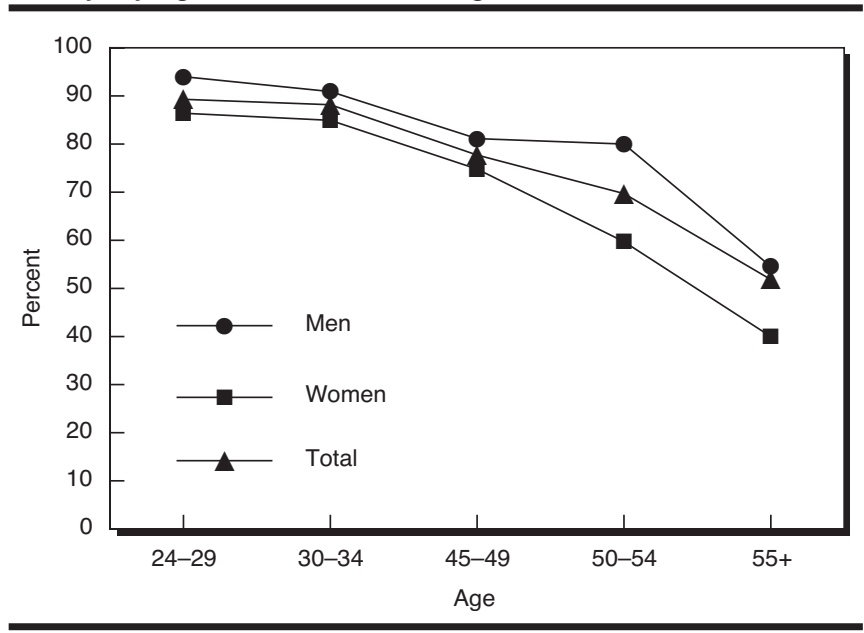

Note: Individuals aged 35-44 were not sampled for the study (see text).
Table 4 Percentage of survey respondents who reported having had marital sex, by sex and age, and percentage distribution of frequency of marital sex and person who initiated sex for those who had sex in the month prior to the survey, by sex and age, Hai Duong Province, Vietnam, 2001

\begin{tabular}{|c|c|c|c|c|}
\hline \multirow[b]{2}{*}{ Variable } & \multicolumn{2}{|c|}{ Men } & \multicolumn{2}{|c|}{ Women } \\
\hline & $\begin{array}{l}\text { Self- } \\
\text { reported }\end{array}$ & $\begin{array}{r}\text { Reported by } \\
\text { women with } \\
\text { husband in } \\
\text { age range }\end{array}$ & $\begin{array}{r}\text { R } \\
\text { Self- } \\
\text { reported }\end{array}$ & $\begin{array}{r}\text { eported by } \\
\text { men with } \\
\text { wife in } \\
\text { age range }\end{array}$ \\
\hline \multicolumn{5}{|l|}{ All respondents } \\
\hline \multicolumn{5}{|l|}{ Age group } \\
\hline 24-29 & 94.0 & 80.0 & 86.4 & 95.3 \\
\hline $30-34$ & 90.9 & 81.8 & 84.9 & 91.4 \\
\hline $45-49$ & 81.1 & 79.3 & 74.8 & 79.8 \\
\hline $50-54$ & $80.0^{*}$ & 62.7 & 59.7 & 65.3 \\
\hline $55+$ & 54.5 & 51.3 & 40.0 & c \\
\hline Total (unadjusted) & $85.0^{*}$ & - & 77.8 & - \\
\hline Total (adjusted) a & 84.4 & - & 78.4 & - \\
\hline
\end{tabular}

Respondents reporting having had sex in past month

Frequency of marital sex ${ }^{b}$

At least once per week

Two to three times per month $\quad 40.2$

Once per month

Total

40.2
16.6

Had sex more than once

per month (unadjusted)

Had sex more than once

per month (adjusted) a

Person who initiated sex ${ }^{\mathrm{b}}$

Respondent

Spouse

Both equally

Total

$83.4^{*}$

$-\quad 38.8$
$-\quad 36.5$

-36.8
$-\quad 36.7$

- 24.7

100.0

100.0

$-\quad 75.3$

78.4

- 76.1

76.1

52.4

7.4

40.2

100.0

*Association with respondent's sex significant at $p \leq 0.05 . \quad-=$ Not applicable. Note: Individuals aged 35-44 were not sampled for the study (see text).

a Adjusted for respondent's age and the age difference between the husband and wife as assessed by the respondent. $\quad{ }^{\mathrm{b}}$ Association with respondent's sex as obtained from a chi-square test significant at $p \leq 0.05$. " ${ }^{\circ}$ Too few observations were made in this category to calculate a percentage.

by men of the same age. An explanation for the lower rates of sexual activity among women is the age difference between spouses (Marsiglio and Donnelly 1991; Knodel and Chayovan 2001). As shown in Table 1, husbands are, on average, about 2.8 years older than their wives. Because men's sexual activity declines with age, a partial explanation for the lower levels of sexual activity reported by women than by men of the same age is that, on average, women have slightly older spouses than men have. The widening of the gender differences after age 49 could be the result of the increased importance of aging in influencing the frequency of male (and hence female) sexual intercourse either through biological or social mechanisms.

Accordingly, the unadjusted and adjusted percentages for having had sex in the past month and frequency of sex during this period are compared here for men and women, where the adjustment factors are the age of the 
respondent and the age differences between spouses (shown in Table 4). ${ }^{7}$ If the overall gender gap in sexual activity diminishes after such an adjustment, this decrease would suggest that the less-frequent sexual activity of women is due to the greater age of their spouses. Because one person from each household was interviewed for the survey, spousal reports on sexual activity cannot be compared directly. Following Knodel and Chayovan (2001), however, the reported levels of sexual activity of men (and women) can be compared with the reported levels from women (and men) who have a spouse within the same age range as the respondent. In the absence of systematic measurement error associated with respondents' sex, these proportions should not differ appreciably.

Eighty-five percent of married men and 78 percent of married women report they had sexual intercourse with their spouse in the past month. This 7 percent difference decreases to 6 percent after adjusting for age and spousal age differences, but even after this adjustment men are still more likely than women to report having engaged in marital sexual activity. For men, the levels of sexual activity implied by women having husbands of a similar age are consistently lower. The largest implied gender gap is found in the 50-54 age range (a 17 percent difference). This finding is consistent with data shown in Figure 1, where relative to the 45-49 group, reported levels of sexual activity among men aged 50 to 54 remain virtually unchanged rather than, as one would expect, showing a decline. The level of sexual activity reported by men with a spouse in the same age range as the female respondent is higher than the self-reports of women for all age intervals.

These results indicate a systematic tendency for men to report higher levels of marital sexual activity than women report. In a face-to-face interview, men may be prone to overreport having had sex with their spouse to avoid being perceived as sexual failures or to show off their sexual prowess. Women may be underreporting having had sex with their spouse because of their shyness or discomfort about discussing such private matters. Another explanation may be that men are engaging in extramarital sex more frequently than women and are including these experiences when responding (Knodel and Chayovan 2001). This explanation is not likely to be of central importance, however, given that married men are presumably reluctant to report extramarital activities in a survey in which the items concern marital sex.

Women are about 8 percent more likely than men to report that sex was infrequent or occurred only once in the past month. Men are more likely to report that sex occurred several times per month or weekly. The greater propensity of men than women to report that sex occurred more than once a month is not significant after adjusting for age and spousal age differences. The relevance of gender also extends to reports of who initiates sex. Although 52 percent of men report having done so, only 8 percent of women say that they themselves did. Because about half of the men surveyed report initiating sex, we would expect a similar proportion of women, on average, to report that their husband is the initiator. Nearly 70 of the women surveyed, however, stated that their spouse initiated intercourse. Men are almost two times more likely than women to state that both spouses initiated intercourse. Other findings also suggest that women are more likely than men to view their spouse as being sexually aggressive. For example, when respondents are asked whether they worry that their spouse is interested in someone else when he/she is away, women are about two times more likely than men to agree that this is a concern (27 percent and 14 percent, respectively) (not shown).

Table 5 presents respondents' reports of having had premarital sex by sex and age. About 12 percent of men and 2 percent of women report that they had sexual intercourse before they were married. Similar differences are found in the Philippines, Singapore, and Thailand. These results reflect the social norm that women remain virgins until they are married (Caraël 1995). The second and third rows of Table 5 show results conditional on having engaged in premarital sex. These percentages are based on very few cases $(\mathrm{N}=8)$ for women. For both men and women, the norm is to have sex for the first time with another unmarried person. Although 16 percent of men say they married their first premarital sexual partner, nearly two-thirds of the women report having done so. Rates of premarital sex generally decline with age, but are similar for those between ages 24-29 and 30-34.

Table 6 shows the associations between premarital sex, having had sex in the past month, having had sex more than once in the past month, and respondent's initiation of sex (or initiation by respondent and spouse equal-

Table 5 Percentage of survey respondents who reported having had premarital sex and its marital outcome, by sex and age, Hai Duong Province, Vietnam, 2001

\begin{tabular}{lrr}
\hline Premarital sex/marital outcome & Men & Women \\
\hline Had premarital sex & $12.3^{* *}$ & 2.0 \\
Of those who had sex before marriage: & & \\
$\quad$ Had first intercourse with an unmarried partner & 96.0 & 87.5 \\
$\quad$ Eventually married the person with whom & $16.3^{* *}$ & \\
$\quad$ they had first sexual intercourse & & 62.5 \\
Age-specific rates of premarital sex for total sample & & \\
24-29 & 8.4 \\
30-34 & 7.9 \\
45-49 & 5.7 \\
50+ & 3.0 \\
(N) & $(57)$ \\
**Association with gender is significant at $p \leq 0.01$. & \\
Note: Individuals aged 35-44 were not sampled for the study (see text).
\end{tabular}

Note: Individuals aged 35-44 were not sampled for the study (see text). 
Table 6 Percentage of survey respondents who reported having had premarital sex and having marital sex, and whether respondent initiated sex with spouse, by selected characteristics, Hai Duong Province, Vietnam, 2001

\begin{tabular}{|c|c|c|c|c|c|c|c|}
\hline \multirow[b]{2}{*}{ Characteristic } & \multirow{2}{*}{$\begin{array}{c}\begin{array}{c}\text { Had premarital } \\
\text { intercourse }\end{array} \\
\text { Total }\end{array}$} & \multicolumn{2}{|c|}{$\begin{array}{l}\text { Had sex with spouse } \\
\text { in past month }\end{array}$} & \multicolumn{2}{|c|}{$\begin{array}{l}\text { Had sex with spouse more } \\
\text { than once in past month }\end{array}$} & \multicolumn{2}{|c|}{$\begin{array}{l}\text { Respondent initiates } \\
\text { sex solely or equally } \\
\text { with spouse }\end{array}$} \\
\hline & & Men & Women & Men & Women & Men & Women \\
\hline \multicolumn{8}{|l|}{ Educational level completed } \\
\hline Primary or lower secondary ${ }^{a}$ & 6.1 & 85.1 & 77.1 & 74.8 & 74.2 & 51.6 & 3.1 \\
\hline Upper secondary+ & 8.7 & 85.8 & $85.4^{\star}$ & $84.4^{*}$ & 81.5 & 51.4 & $10.9^{\star}$ \\
\hline \multicolumn{8}{|l|}{ Quartiles of household-wealth index } \\
\hline Lowest $^{a}$ & 6.9 & 87.2 & 69.5 & 76.7 & 69.9 & 54.0 & 11.7 \\
\hline Second & 4.1 & 78.4 & 79.0 & 72.0 & 74.9 & 53.7 & 11.2 \\
\hline Third & 8.5 & 86.3 & $87.6^{\star \star}$ & 83.0 & 77.6 & 58.2 & 5.9 \\
\hline Highest & 9.0 & 90.0 & $83.2^{* *}$ & 81.8 & $82.0^{*}$ & $38.4^{*}$ & 5.7 \\
\hline \multicolumn{8}{|l|}{ Residential history } \\
\hline Grew up and lives in urban area ${ }^{a}$ & 14.5 & 89.2 & 84.9 & 76.4 & 78.0 & 45.7 & 7.7 \\
\hline Grew up in rural area/lives in urban area & 9.9 & 85.7 & 83.8 & 81.0 & 79.6 & 49.8 & 5.3 \\
\hline Always lived in rural area & $3.0^{* *}$ & 84.3 & 74.9 & 77.2 & 72.9 & 53.7 & 11.5 \\
\hline \multicolumn{8}{|l|}{ Marriage cohort } \\
\hline $1965-75^{a}$ & 3.1 & 76.2 & 77.1 & 72.8 & 67.4 & 61.0 & 30.1 \\
\hline 1976-85 & 4.0 & 84.8 & 81.7 & 81.0 & 72.6 & 52.0 & 22.3 \\
\hline $1986-92$ & 6.9 & 90.7 & 80.5 & 80.0 & 85.9 & 50.3 & 6.7 \\
\hline 1993-2000 & $14.7^{\star *}$ & 92.6 & 70.8 & 85.0 & 90.4 & 41.8 & $0.81^{*}$ \\
\hline
\end{tabular}

ly) with educational level, household-wealth-index quartile, urban and rural residence, and marriage cohort. The percentages for marital sex are adjusted for age and for spousal age differences. As noted above, the correlation between age and marriage cohort is negative and near unity; therefore, it is not possible to assess the role of each of these two characteristics separately.

Among women, educational attainment is positively associated with reporting having had sex with one's spouse in the previous month as well as with initiating sex. Reporting having had sex more than once in the past month is positively related to education, although the association is statistically significant only for men. Compared with those in the lowest asset quartiles, women in a wealth category higher than the median are more likely to report having had sex, and in the highest quartile having had more frequent sex, than those in the other quartiles. Men in the highest wealth category are least likely to report that they initiate sex with their spouse either solely or jointly. The reported level of premarital sex is lowest for rural residents, intermediate for those who grew up in rural areas, and highest for individuals who have always resided in an urban commune. Individuals in the most recent marriage cohorts are more likely to report having had premarital sex than are those in the older cohorts. The differences between the two marriage cohorts after 1985 are significant $(p<0.05)$. Net of age, women in the post-1985 cohorts are more likely to report having had frequent sex with their husbands in the past month, but are less likely to report initiating sex than are those married for longer durations.

\section{Conclusion}

In Hai Duong Province, Vietnam, attitudes about premarital and extramarital sex generally remain conservative. Most respondents in urban and rural areas do not agree with the notion that extramarital sex or that sex and expressions of intimacy before marriage are acceptable. A trend toward less disapproval of sex outside marriage has emerged, however, particularly among men who were married after the economic reforms that began in the mid-1980s. The most pronounced decline in men's disapproval concerns having sex with a future spouse. Even among the most recent marriage cohorts, however, 40 percent of the men surveyed and about 70 percent of the women still strongly disagree that having premarital sex with a future spouse is acceptable. Among men who married in recent years, disapproval of engaging in sexual activity with someone you do not intend to marry and of extramarital sex is declining, but the proportion of the respondents in this study who disapprove remains above a majority.

About 12 percent of men and 2 percent of women surveyed report having experienced their first sexual intercourse before marriage. Estimates indicate that in a range of settings in Africa, Asia, and Latin America, 36 
to 92 percent of men of comparable age are no longer virgins at the time of their marriage (Caraël 1995). Levels in Hai Duong Province are substantially lower. Among women, these findings resemble those from Thailand, where 3 percent of women are estimated to have had sex before marrying (Caraël 1995). Premarital sexual activity is more common among urban residents and has increased successively for recent marriage cohorts to 15 percent for those married after 1992. This level is still well below estimates for other countries. The results of this study support the assertion of a number of qualitative studies (for example, Bélanger and Khuat 1999 and Gammeltoft 2002) that if women engage in premarital sex, typically they do so as a precursor to marriage. The low levels of reported premarital sex are consistent with the finding that in Vietnam the HIV epidemic is concentrated among intravenous drug users. Nevertheless, a need exists for ongoing monitoring of trends in sexual behavior, particularly regarding commercial sex workers (Vu et al. 2000).

The level of sexual intercourse within marriage in Hai Duong Province is similar to results for the United States for some age ranges. Rao and Demaris (1995) report that about 82 percent of their US sample of married respondents from the 1988 National Survey of Families and Households reported having had sex with their partner in the past month. Compared with estimates for the US from Call and his colleagues (1995), the findings of this study are similar for those between ages 24 and 34 and ages 50 and 54 . For the $45-49$ and $50-54$ age groups, this study yields a level that is higher by 6 to 7 percent. The results are also generally similar to those reported for Singapore and Thailand (Caraël 1995; Knodel and Chayovan 2001). However, men and women in this study sample report having engaged more frequently in sex within marriage than did those in Manila by about 14 and 11 percent, respectively (Caraël 1995). ${ }^{8}$ Married women in Hai Duong Province with higher education and greater wealth and those belonging to recent marriage cohorts are more likely to report having had sex or having frequent sex. Whether these reports can be taken to mean that these groups engage in sex more frequently than others is unclear; at a minimum, they suggest their greater willingness to disclose information about their sexual activity. No support is found for a markedly lower incidence of sexual activity in rural compared with urban areas, as has been suggested by anecdotal evidence (for example, see Pham 1999). A decline in sexual activity is a function of increasing age, and, for each age group, pronounced gender differences are evident in reported frequency of sexual intercourse (see Knodel and Chayovan 2001).

Men of all ages tend to report greater frequency of sexual activity than women of the same age report. This discrepancy is most pronounced in the oldest age range. A suggested explanation for this discrepancy is that women tend to have older spouses than men have and, therefore, are likely to engage in less frequent marital sex than men of the same age with younger spouses. Another part of the explanation may be that women are underreporting the frequency with which they have sex. Evidence for such underreporting is the finding that women report lower levels of marital sex than do men with a spouse of similar age. These patterns, consistent with evidence from Thailand and elsewhere in Vietnam, suggest that the expression of sexuality is seen as more legitimate and natural for men than for women. Other findings lend support to the assumption that Vietnamese women are more reticent than men about sexual matters. Women are considerably less likely than men to report initiating sex or initiating sex jointly with their spouse. They are significantly more likely than men to express conservative views about sex before or outside of marriage and to feel anxious about their spouse's infidelity.

This study is a preliminary step toward understanding the evolving nature of sexual mores and sexuality in Vietnam. The results are not representative of Vietnam, and further research is needed that examines patterns of sexual attitudes and behaviors using larger probability samples. Studies that compare findings across northern and southern regions are needed to elucidate how differing political histories and levels of openness to the West have shaped Vietnamese sexuality. The implications of research design for measuring sexuality can be addressed by comparing results from face-to-face interviews, self-administered questionnaires, audio-assisted technology, and qualitative studies (see Mensch et al. 2003b for an application to Kenya). Such research will provide insight about systematic differences in women's and men's reports of sexual activity described here and contribute to better measurement of sexual expression in Vietnam and elsewhere.

\section{Notes}

1 Khuat (1998) is an exception; that study was based on discussions with four focus groups and on in-depth interviews with married and unmarried individuals from Hanoi born between 1957 and 1978.

2 Another behavior viewed as permissible for Vietnamese men but not for women is smoking. Women who smoke are described as "bad," "unfeminine," and pitiable (Morrow et al. 2002).

3 Chronbach's alpha is a measure of the internal consistency of a set of items. Alpha ranges from 0 to 1 and increases in value as more items are considered and the average interitem correlation increases. A value above 0.70 can be taken to indicate an acceptable level of consistency within a set of items (Spector 1992). 
4 Principal components is a statistical procedure that assigns weights by extracting orthogonal linear combinations of variables that most successfully capture the common variance in a set of items (see Filmer and Pritchett [2001] and references therein). This is one method for assessing household economic status using proxy data compared, for example, with assigning all items equal weights through additive summaries.

5 Before administering this survey, interviewers were instructed to assure respondents that their answers would remain confidential, that they could refuse to answer any of the questions, and that the only requirement was their signature to indicate their voluntary participation.

6 Bohrnstedt (1983) refers to this sort of evaluation as the concurrent form of criterion validity, whereby a measure is evaluated through correlations with other variables based on theory and the available evidence. The findings that younger, more educated or urban respondents are more accepting of premarital sexual activity with a future partner and that women are more conservative than men in their views concerning sexual behavior are consistent with the patterns that have been suggested for the Vietnamese context based on the previous studies reviewed here.

7 The results are adjusted for age of respondent and for age differences between spouses (as linear terms) using logistic regression. The adjusted results are virtually identical if a categorical variable for age is used, as in Knodel and Chayovan (2001). A multinomial logit for frequency of sexual intercourse by sex indicated no significant differences in reporting "two to three times a month" compared with "at least once a week" among men compared with women. Thus, unadjusted and adjusted means for frequency of intercourse are shown for these two groups (monthly or more often) compared with "once a month." Values for sexual initiation are not adjusted for age or age differences because no consistent association with age is observed for this variable.

8 Similar to Knodel and Chayovan (2001), the difficulty is noted here of making precise comparisons with the results from the United States. For the US, Call et al. (1995) show only graphical results by age. Rao and Demaris (1995) show a distribution of coital frequency (including zero) during the past month for a sample of cohabiting or married couples who entered their unions in the five years before the 1988 survey. Neither study shows results separately by sex. The estimates from Call et al. (1995), where the missing values are assumed to represent people who did not have sex, are used for comparison with the findings from this analysis. Knodel and Chayovan (2001) examine married men and women older than 50 . The findings presented here are similar to what they report except for married men aged 50-54. In this group, 80 percent of our sample reported having had sex in the past month, whereas in their study, the level is 69 percent. As Mensch et al. (2003b) point out, variance in sexual behavior in different contexts likely reflects variable data-collection methods, sampling frames, willingness to report sexual behavior, and other forms of measurement error, and cannot be assumed to reflect cultural similarities or dissimilarities.

\section{References}

Barr, Cameron. 1997. “Vietnam's new war: 'Social evils' too global?" The Christian Science Monitor 24 September: 1-3.

Bélanger, Danièle and Thu Hong Khuat. 1996. "Marriage and the family in urban North Vietnam, 1965-1993." Journal of Population 2(1): 83-112.
1998. "Young single women using abortion in Hanoi, Vietnam." Asia-Pacific Population Journal 13(2): 3-26.

. 1999. "Single women's experiences of sexual relationships and abortion in Hanoi, Vietnam." Reproductive Health Matters 7(14): $71-82$.

Bohrnstedt, George W. 1983. "Measurement." In Handbook of Survey Research. Eds. Peter H. Rossi, James D. Wright, and A.B. Anderson. New York: Academic Press.

Call, Vaughn, Susan Sprecher, and Pepper Schwartz. 1995. "The incidence and frequency of marital sex in a national sample." Journal of Marriage and the Family 57(3): 639-652.

Caraël, Michel. 1995. "Sexual behavior." In Sexual Behavior and AIDS in the Developing World. Eds. John Cleland and Benoît Ferry. London: Taylor and Francis. Pp. 75-123.

Chittick, John. 1996. “The coming wave: HIV / AIDS in Vietnam: Observations and recommendations on Ho Chi Minh City's HIV/ AIDS programs." Boston: Published by the author

Committee for Population, Family, and Children [Vietnam] and ORC Macro 2003. Vietnam Demographic and Health Survey 2002. Hano and Calverton, MD: General Statistical Office, Committee for Population, Family, and Children, and ORC Macro.

Dang, Anh, Sidney Goldstein, and James McNally. 1997. "Internal migration and development in Vietnam." International Migration Review 31(2): 312-337

Dare, O.O. and John G. Cleland. 1994. "Reliability and validity of survey data on sexual behaviour." Health Transition Review 4 (supplement): 93-110.

Efroymson, Debra. 1996. "Vietnam faces modern sexuality problems with inadequate knowledge and solutions." SIECUS Report 24(3): 4-6.

Efroymson, Debra, Vo Phim Nguyan Thanh, and Nguyen Quunh Trang. 1997. Confusions and Contradictions: Results of Qualitative Research on Youth Sexuality. Ottawa: PATH Canada.

Eisen, Arlene. 1984. Women and Revolution in Vietnam. London: Zed Books.

Filmer, Deon and Lant Pritchett. 2001. "Estimating wealth effects without expenditure data-or tears: An application to educational enrollments in states of India." Demography 38(1): 115-132.

Gammeltoft, Tine. 2001. "Faithful, heroic, resourceful: Changing images of women in Vietnam." In Vietnamese Society in Transition: The Daily Politics of Reform and Change. Ed. John Kleinman. Amsterdam: Het Spinhuis. Pp. 265-280.

. 2002. "The irony of sexual agency: Premarital sex in urban northern Vietnam." In Gender, Household, State: Doi moi in Vietnam. Eds. Jayne Werner and Danièle Bélanger. Ithaca, NY: Cornell University. Pp. 111-128.

. 2003. "Being special for somebody: Urban sexualities in contemporary Vietnam." Asian Journal of Social Science 30(3): 476-492.

Go, Vivian Fei-ling, Vu Minh Quan, A. Chung, Jonathan Zenilman, Vu Thi Minh Hanh, and David Celentano. 2002. "Gender gaps, gender traps: Sexual identity and vulnerability to sexually transmitted diseases among women in Vietnam." Social Science \& Medicine 55(3): 467-481.

Goodkind, Daniel. 1994. "Abortion in Vietnam: Measurements, puzzles, and concerns." Studies in Family Planning 25(6): 342-352.

- 1995. "Marriage Style, Development, and Spousal Distances: Sex and the Transition to Parenthood in a Province of North Vietnam, 1948-1993." University of Michigan Population Studies Center Research Report No. 95-348. 
1996. "State agendas, local sentiments: Vietnamese wedding practices amidst socialist transformations." Social Forces 75(2): $717-742$.

Goodkind, Daniel and Phan Thuc Anh. 1997. "Multi-method Approaches for Research on Sex and HIV / AIDS: Some Results of a Pilot Study of Young Adults in Hanoi." University of Michigan Population Studies Center Research Report No. 97-407.

Hardee, Karen, Pamela Pine, and Lauren Taggart Wasson. 2003. Adolescent and Youth Reproductive Health in the Asia and Near East Region: Status, Issues, Policies and Programs. Washington, DC: The Futures Group International.

Haub, Carl and Phuong Thi Thu Huong. 2003. Adolescents and Youth in Vietnam. Hanoi and Washington, DC: Center for Population Studies and Information and the Population Reference Bureau.

Hy, Van Luong. 1992. Revolution in the Village: Tradition and Transformation in North Vietnam, 1925-1988. Honolulu: University of Hawaii Press.

Khuat, Thu Hong. 1998. "Study on Sexuality in Vietnam: The Known and Unknown Issues." The Population Council Regional Working Papers No. 11. Hanoi, Vietnam.

- 2003. Adolescent and Youth Reproductive Health in Vietnam: Status, Issues, Policies and Programs. Washington, DC: The Futures Group International.

Knodel, John and Napaporn Chayovan. 2001. "Sexual activity among older Thais: The influence of age, gender and health." Journal of Cross-Cultural Gerontology 16(2): 173-200.

Knodel, John, Chanpen Saengtienchai, Mark Vanlandingham, and Rachel Lucas. 1999. "Sexuality, sexual experience, and the good spouse: Views of married Thai men and women." In Genders and Sexualities in Modern Thailand. Eds. Peter A. Jackson and Nerida M. Cook. Chiang Mai, Thailand: Silkworm Books. Pp. 93-113.

Long, Lynellyn D., Lyn Nguyen Henderson, Le Thi Phuong Mai, and Carl Haub. 2000. The Doi Moi Generation: Coming of Age in Vietnam Today. Hanoi: Population Council.

Marsiglio, William and Denise Donnelly. 1991. "Sexual relations in later life: A national study of married persons." Journal of Gerontology: Social Sciences 46(6): S338-S344.

Mensch, Barbara S., Wesley H. Clark, and Dang Nguyen Anh. 2003a. "Adolescents in Vietnam: Looking beyond reproductive health." Studies in Family Planning 34(4): 249-262.

Mensch, Barbara S., Paul C. Hewett, and Annabel S. Erulkar. 2003b. "The reporting of sensitive behavior by adolescents: A methodological experiment in Kenya." Demography 40(2): 247-268.
Morrow, Martha, Do Hong Ngoc, Truong Trong Hoang, and Tran Hue Trinh. 2002. "Smoking and young women in Vietnam: The influence of normative gender roles." Social Science $\mathcal{E}$ Medicine 55(4): 681-690.

Pham, Van Bich. 1999. The Vietnamese Family in Change: The Case of the Red River Delta. Richmond, Surrey, England: Curzon Press.

Rao, K.V. and Alfred Demaris. 1995. “Coital frequency among married and cohabiting couples in the United States." Journal of Biosocial Science 27(2): 135-150.

Rindfuss, Ronald R. and S. Philip Morgan. 1983. "Marriage, sex, and the first birth interval: The quiet revolution in Asia." Population and Development Review 9(2): 259-278.

Rydstrom, Helle. 2003. Embodying Morality: Growing Up in Rural Northern Vietnam. Honolulu: University of Hawaii Press.

Spector, Paul E. 1992. Summated Rating Scale Construction. Quantitative Applications in the Social Sciences, No. 82. Newbury Park, CA: Sage Publications.

Turner, Charles F., Heather G. Miller, and Susan M. Rogers. 2001. "Survey measurement of sexual behavior: Problems and progress." In Researching Sexual Behavior: Methodological Issues. Ed. John Bancroft. Bloomington, IN: Indiana University Press.

Vu, Quy Nhan. 1996. Reproductive Behaviour of Unmarried Urban Students of Age 17-24 in Vietnam. Hanoi: National Committee for Population and Family Planning and the Center for Population Studies and Information.

Vu, Minh Quan, A. Chung, Hoang Thuy Long, and Timothy J. Dondero. 2000. "HIV in Vietnam: The evolving epidemic and the prevention response, 1996 through 1999." Journal of Acquired Immune Deficiency Syndromes 25(4): 360-369.

Xenos, Peter. 1997. "Survey sheds new light on marriage and sexuality in the Philippines." Asia-Pacific Population \& Policy 42(July): $1-4$.

\section{Acknowledgments}

This research was supported by a grant from the National Institutes of Health/Fogarty International Center and a National Institute of Child Health and Human Development postdoctoral training fellowship awarded to the University of Michigan. I thank John Knodel and Vu Tuan Huy for helpful comments on an earlier version of this study. 